\title{
Live Population Dynamics of 'Candidatus Liberibacter asiaticus', the Bacterial Agent Associated with Citrus Huanglongbing, in Citrus and Non-Citrus Hosts
}

\author{
H. Hu, Avijit Roy, and R. H. Brlansky, Institute of Food and Agriculture Sciences, Citrus Research and Education Center, University \\ of Florida, Lake Alfred 33850
}

\begin{abstract}
Hu, H., Roy, A., and Brlansky, R. H. 2014. Live population dynamics of 'Candidatus Liberibacter asiaticus', the bacterial agent associated with citrus huanglongbing, in citrus and non-citrus hosts. Plant Dis. 98:876-884.

Citrus huanglongbing (HLB) is a century-old destructive disease which presents an unprecedented challenge to citrus industries worldwide. In Florida, HLB is associated with the phloem-limited bacterium 'Candidatus Liberibacter asiaticus' and is mainly transmitted by Asian citrus psyllid (Diaphorina citri). Quantification of the pathogen population in a host aids in investigation of virulence mechanisms and disease management. Recently a procedure was developed to detect live bacterial populations using a novel DNA-binding dye, propidium monoazide, in conjunction with real-time polymerase chain reaction (PMA-qPCR). Chinese box orange (Severinia buxifolia) is a common ornamental

20 months, the change of the live ' $\mathrm{Ca}$. L. asiaticus' populations in graft- and psyllid-transmitted Valencia sweet orange (Citrus sinensis 'Valencia') and S. buxifolia plants was monitored by PMA-qPCR. Our results showed that the live ' $\mathrm{Ca}$. L. asiaticus' population was significantly lower in the months of December, January, and February than the rest of the year in both hosts. No statistically significant pattern in the total bacterial population was observed in either host. This pattern may indicate a seasonal growth of ' $\mathrm{Ca}$. L. asiaticus' along with the growth of both plants. These new findings should provide useful information on HLB management.
\end{abstract} present in Florida which could host $\mathrm{D}$. citri and ' $\mathrm{Ca}$. L. asiaticus'. For
Citrus huanglongbing (HLB) is currently the most devastating citrus disease in the world. It can cause premature fruit drop and eventually kill the infected trees. Three types of HLB have been reported, and they are associated with three phloem-restricted bacterial agents: 'Candidatus Liberibacter asiaticus' $(2,13,30)$, ' $C a$. L. africanus' $(11,27)$, and ' $C a$. L. americanus' (31). These fastidious bacteria have not been obtained in pure culture yet, which poses a major obstacle in HLB research (8). Most (if not all) of the citrus cultivars are susceptible to HLB and, when infected, the production and life span of the diseased citrus trees are greatly reduced $(2,33)$.

HLB affects all major citrus producing areas in the world, such as the United States, China, and Brazil, and causes substantial economic losses (2). Furthermore, there is no cure for this disease yet; therefore, HLB has posed an unprecedented challenge to citrus industries worldwide (33). Although HLB is graft transmissible, it is mainly spread by citrus psyllids in the field $(2,33)$. There are two citrus psyllid species responsible for the transmission: Asian citrus psyllid (ACP, Diaphorina citri) in Asia and the Americas $(2,13,30)$ and African citrus psyllid (Trioza erytreae) in Africa (2). In the United States, HLB (the only bacterial agent found is ' $\mathrm{Ca}$. L. asiaticus', spread by ACP) is expanding to new citrus production areas since its first report in south Florida in 2005 (13). As of 2013, the ACP has been found in Florida, Texas, California, Arizona, Louisiana, Georgia, Mississippi, Hawaii, and Alabama, while HLB has been reported in Florida (2005), Louisiana (2008), South Carolina (2009), Georgia (2009), and, most recently, in Texas and California (2012) $(10,13,33)$.

Corresponding author: R. H. Brlansky, E-mail: rhby@ufl.edu

Accepted for publication 6 February 2014.

http://dx.doi.org/10.1094/PDIS-08-13-0886-RE

(c) 2014 The American Phytopathological Society
Many citrus relatives in the family Rutaceae are present in Florida as ornamentals; for example, Murraya spp., Choisya spp., Severinia buxifolia, Calamondin ( $\times$ Citrofortunella microcarpa), and more. Considering their potential role as alternative hosts (either for the psyllid vector or the bacterial agents), citrus relatives require more studies to enable integrated management of HLB (33). Alternative hosts are concealed havens for pathogens and usually play an important role in the disease epidemiology, especially when they are not recognized (16). However, studies on alternative hosts of HLB are quite limited to date. Halbert and Manjunath summarized two lists of alternative hosts for D. citri and Liberibacter spp., respectively, in which most of the hosts are recognized based on field surveys or polymerase chain reaction (PCR) tests (i.e., no systematic studies were conducted to establish their alternative host status; 12 ). Studies have shown that ' $\mathrm{Ca}$. L. asiaticus' could be detected in some citrus relatives; for example, Murraya paniculata $(4,5,36)$, Clausena lansium $(5,7)$, and Limonia acidissima L. (16,19). However, most of the studies were mainly diagnostic work with field samples (5-7). Hung et al. (17) reported $S$. buxifolia as an alternative host of HLB based on grafting and psyllid-transmission experiments but psyllid transmission between $S$. buxifolia plants was not studied, and the bacterial presence inside $S$. buxifolia was not quantified because conventional PCR was used.

Besides premature fruit drop and plant death, typical HLB symptoms on citrus include leaves with blotchy mottle, small leaves, yellow shoots, corky veins, misshapen and discolored fruit, and aborted seed (2). However, HLB diagnosis cannot rely on symptoms due to confusion with other disorders and the latent period in infected trees (6 to 12 months, if not longer; 2). Current HLB diagnosis and research mainly uses DNA-based methods such as real-time quantitative PCR (qPCR). qPCR alone cannot differentiate between live and dead cells (14). The bacterial population detected by qPCR is the total genome present (TGP) in the sample; that is, the sum of live bacteria, dead bacteria (with integrity-compromised cell structure), and naked DNA. The detection of 
the TGP may fulfill diagnostic purpose but the information obtained from TGP is limited (14), especially if the genomes of live bacteria (GLB) is the focus. There are several studies on bacterial populations in HLB-affected citrus hosts. Some showed the bacterial distribution in different tissue or parts of the host plants $(9,29)$ and some showed the year-round fluctuation of the bacterial populations in different citrus hosts $(15,34)$. However, there was mixed information from different research; for example, the peak time of ' $\mathrm{Ca}$. L. asiaticus' population in citrus hosts was reported to be from September to December (15), whereas Wang et al. (34) reported that September was one of the months with lowest bacterial population. With a novel cell membrane-impermeant DNA-binding dye, propidium monoazide (PMA), the DNA from dead bacteria can be removed in a pretreatment before the total DNA extraction, which leaves only the DNA from live bacteria for detection in the subsequent qPCR $(14,24)$. PMA-qPCR has been successfully applied for many bacterial pathogens to detect the live bacterial populations $(18,21,25,35)$ but there are no systemic applications, except for the initial published method with the HLB-associated bacteria (14).

In this study, grafting and psyllid-transmission experiments involving citrus and $S$. buxifolia were first done in the greenhouse, and samples from these synchronized plants were tested on a monthly basis by PMA-qPCR to determine the live ' $\mathrm{Ca}$. L. asiaticus' population dynamics in citrus and $S$. buxifolia host plants, which may reveal certain growth pattern of the uncultured bacterial pathogen.

\section{Materials and Methods}

Plants and psyllid materials. Seedlings of $S$. buxifolia were germinated from seed collected at the Citrus Research and Educa- tion Center of the University of Florida, Lake Alfred. The source plants were assumed and later confirmed to be ' $\mathrm{Ca}$. L. asiaticus'free by the HLBasrp qPCR assay (20; Table 1). Valencia sweet orange (Citrus sinensis 'Valencia') seedlings were germinated from seed obtained from California. Citrus and Severinia seedlings were grown for 2 to 3 months in an insect-free greenhouse with ambient temperature and daylight. Healthy seedlings of $S$. buxifolia and citrus were moved to a second growth room with controlled temperature of $25 \pm 1^{\circ} \mathrm{C}$ and controlled artificial light of $12 \mathrm{~h}$ each day (referred to as the "psyllid room"). HLB-affected 'Rough' lemon $(C . \times$ jambhiri Lush.) plants were kept in the psyllid room to rear ' $\mathrm{Ca}$. L. asiaticus'-positive psyllids for inoculation purposes. All of the psyllid-transmission experiments were set up in the psyllid room and kept for the first 2 months post inoculation (PI), after which psyllids were collected off the plants and the plants were washed with tap water, sprayed with insecticides, and then moved to the third greenhouse with controlled temperature of $25 \pm 1{ }^{\circ} \mathrm{C}$ and natural light for qPCR monitoring and symptom observation.

Healthy Asian citrus psyllids (D. citri) were collected from $M$. paniculata ornamentals and released in a 60-by-60-by-90-cm Rearing and Observation Cage (BioQuip Products Inc.) with several sweet orange $(C$. sinensis) and $M$. paniculata plants (referred to as the "healthy cage"). A psyllid colony was established in the healthy cage. Psyllids and plants kept in this cage were constantly monitored by qPCR to ensure a ' $\mathrm{Ca}$. L. asiaticus'-free condition (Table 1).

Inoculation procedure. Graft-inoculation was conducted on 2year-old $S$. buxifolia and Valencia sweet orange (C. sinensis Valencia) plants using the budding method. All the inoculation buds were collected from HLB-affected Rough lemon $(C . \times$ jambhiri Lush.) plants with typical blotchy mottle symptoms. All graft inoculation was done in July 2009. Four months after grafting, leaves

Table 1. Primers and probes used in real-time and conventional polymerase chain reaction assays ${ }^{\mathrm{a}}$

\begin{tabular}{|c|c|c|c|c|c|}
\hline Assay & Sequence $\left(5^{\prime} \rightarrow 3^{\prime}\right)$ & Region & $\begin{array}{l}\text { Conc. } \\
(\mathbf{n M})\end{array}$ & $\begin{array}{l}\text { Product } \\
\text { (bp) }\end{array}$ & Ref. \\
\hline \multirow[t]{3}{*}{ HLBasrp } & TCGAGCGCGTATGCAATACG & $\begin{array}{l}\text { 16S rDNA of 'Candidatus } \\
\text { Liberibacter asiaticus' }\end{array}$ & 250 & 75 & 20 \\
\hline & GCGTTATCCCGTAGAAAAAGGTAG & $\ldots$ & 250 & $\ldots$ & $\ldots$ \\
\hline & (FAM)-AGACGGGTGAGTAACGCG-(BHQ-1) ${ }^{\mathrm{b}}$ & $\ldots$ & 150 & $\ldots$ & $\ldots$ \\
\hline \multirow{3}{*}{ COXfrp } & GTATGCCACGTCGCATTCCAGA & Cytochrome oxidase (COX) gene & 300 & 68 & 20 \\
\hline & GCCAAAACTGCTAAGGGCATTC & $\ldots$ & 300 & $\ldots$ & $\ldots$ \\
\hline & (JOE)-ATCCAGATGCTTACGCTGG-(BHQ-2) ${ }^{\mathrm{b}}$ & & 150 & & \\
\hline \multirow[t]{3}{*}{ WGfrp } & GCTCTCAAAGATCGGTTTGACGG & Glycoprotein gene wingless $(\mathrm{wg}$ ) & 300 & 74 & 23 \\
\hline & GCTGCCACGAACGTTACCTTC & $\ldots$ & 300 & $\ldots$ & $\ldots$ \\
\hline & (JOE)-TTACTGACCATCACTCTGGACGC-(BHQ-2)b & $\ldots$ & 150 & $\ldots$ & $\ldots$ \\
\hline \multirow[t]{4}{*}{ CQUfrp } & TGGAGGTGTAAAAGTTGCCAAA & 50S ribosomal protein $\mathrm{L} 10(\mathrm{rplJ})$ of & & & \\
\hline & & 'Ca. L. asiaticus' & 800 & 87 & 34 \\
\hline & CCAACGAAAAGATCAGATATTCCTCTA & $\ldots$ & 800 & $\ldots$ & $\ldots$ \\
\hline & $\begin{array}{l}\text { (FAM)-ATCGTCTCGTCAAGATTGCTATCCGTGATACTAG- } \\
\text { (TAMRA) }^{\mathrm{b}}\end{array}$ & $\cdots$ & 400 & $\cdots$ & $\cdots$ \\
\hline \multirow[t]{3}{*}{ rpoBfrp } & TGAGGAGAARCRATGGCDAAAGGYc & $\begin{array}{l}\beta \text {-Subunit of RNA polymerase } \\
(\text { rpoB })\end{array}$ & 400 & 110 & 1 \\
\hline & CTGAACTTCAAYGAGATCAGGTATGTC ${ }^{c}$ & $\ldots$ & 400 & $\ldots$ & $\ldots$ \\
\hline & (FAM)-TTGTGTTCAATGGTCTCGGGCG-(BHQ-1) & $\ldots$ & 200 & $\ldots$ & $\ldots$ \\
\hline \multirow[t]{4}{*}{ Lasfrp } & CGTCTCGTCAAGATTGCTATCCGT & $\begin{array}{l}\text { 50S ribosomal proteins L10 and } \\
\text { L11 }(r p l J / r p l K) \text { of }\end{array}$ & & & \\
\hline & & 'Ca. L. asiaticus' & 250 & 189 & 1 \\
\hline & TTAAGGACGCCCTTCTCTACAACC & .. & 250 & ... & .. \\
\hline & (FAM)-CCTAAAATTTCGGTTAGCTTTTCAAATGACAA-(BHQ-1) & & 150 & $\ldots$ & $\ldots$ \\
\hline \multirow[t]{3}{*}{ Lamfrp } & TGTTGCGCAAATCGGTAGTCTTAG & $\begin{array}{l}\text { 50S ribosome proteins } \mathrm{L} 10 \text { and } \mathrm{L} 11 \\
(\mathrm{rplJ} / \mathrm{rplK}) \text { of 'Ca. L. americanus' }\end{array}$ & 250 & 183 & 1 \\
\hline & GGTGCAGCAACAGGATCTTTGGAA & $\ldots$ & 250 & $\ldots$ & $\ldots$ \\
\hline & (Cy5)-GAAGCGGGAGGATTTGCTAAGGTTGT-(BHQ-2) ${ }^{\mathrm{b}}$ & & 150 & .. & $\ldots$ \\
\hline \multirow[t]{3}{*}{ Laffrp } & AAAGAGGCAGGTGTTAAGTCGGGA & $\begin{array}{l}\text { 50S ribosome proteins L10 and L11 } \\
(r p l J / r p l K) \text { of 'Ca. L. africanus' }\end{array}$ & 250 & 170 & 1 \\
\hline & AAGCCGAACCTTCTACCATGCTCA & $\ldots$ & 250 & $\ldots$ & $\ldots$ \\
\hline & (TAMRA)-TGGGTGCTATTAGCATTGAGGGTGCT-(BHQ-2) ${ }^{\mathrm{b}}$ & $\ldots$ & 150 & & \\
\hline \multirow[t]{2}{*}{ ARfr } & AGTTTGATCMTGGCTCAGAACG ${ }^{\mathrm{c}}$ & $16 \mathrm{~S} / 23 \mathrm{~S}$ rRNA & 400 & 2,588 & TS \\
\hline & CACGGTACTRGTTCACTATCGGTC ${ }^{c}$ & 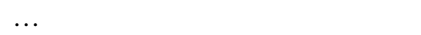 & 400 & $\ldots$ & $\ldots$ \\
\hline
\end{tabular}

${ }^{\mathrm{a}}$ Conc. $=$ final concentration and Ref. $=$ literature citations or developed in this study $(\mathrm{TS})$.

b TaqMan probes.

${ }^{\mathrm{c}}$ Degenerate primer or probe. Codes definition for mixed bases are as follows: $\mathrm{R}=\mathrm{A}$ or $\mathrm{G}, \mathrm{D}=\mathrm{A}$ or $\mathrm{G}$ or $\mathrm{T}, \mathrm{Y}=\mathrm{C}$ or $\mathrm{T}, \mathrm{M}=\mathrm{A}$ or $\mathrm{C}$. 
from the grafted $S$. buxifolia and Valencia sweet orange plants were collected and tested with qPCR to confirm ' $\mathrm{Ca}$. L. asiaticus' infection.

Psyllid transmission was conducted in three possible pathways: pathway 1 , from ' $C a$. L. asiaticus'-infected citrus to healthy $S$. buxifolia; pathway 2, from ' $C a$. L. asiaticus'-infected S. buxifolia to healthy citrus; and pathway 3 from ' $\mathrm{Ca}$. L. asiaticus'-infected $S$. buxifolia to healthy $S$. buxifolia. A standard transmission procedure was followed in each pathway studied. ' $\mathrm{Ca}$. L. asiaticus'-free psyllids $(D$. citri) were collected from the healthy cage and colonized on source plants for a 3-week acquisition access period (AAP; 4). Source plants in transmission pathway 1 (from ' $\mathrm{Ca}$. L. asiaticus'infected citrus to $S$. buxifolia) were ' $C a$. L. asiaticus'-infected Rough lemon plants, whereas ' $\mathrm{Ca}$. L. asiaticus'-infected $S$. buxifolia plants in pathways 2 and 3 were colonized by healthy psyllids. During the AAP, psyllids could mate and reproduce but only adults were used for inoculations $(4,26)$. When new flushes

Table 2. Detection of 'Candidatus Liberibacter asiaticus' in Severinia buxifolia inoculated by psyllids from infected citrus

\begin{tabular}{lcccc}
\hline & \multicolumn{4}{c}{ Quantitative threshold cycle $^{\mathbf{a}}$} \\
\cline { 2 - 5 } Plant $^{\mathbf{b}}$ & $\begin{array}{c}\text { Assay 1 } \\
\text { (2 MPI) }\end{array}$ & $\begin{array}{c}\text { Assay 2 } \\
\text { (5 MPI) }\end{array}$ & $\begin{array}{c}\text { Assay 3 } \\
\text { (8 MPI) }\end{array}$ & $\begin{array}{c}\text { Assay 4 } \\
\text { (12 MPI) }\end{array}$ \\
\hline $1-1$ & 32.9 & 30.2 & 24.9 & 25.3 \\
$1-2$ & 0.0 & 35.0 & 28.6 & 27.9 \\
$1-3$ & 0.0 & 30.8 & 23.3 & 24.5 \\
$2-1$ & 0.0 & 33.0 & 26.5 & 25.6 \\
$2-2$ & 0.0 & 32.4 & 22.5 & 23.2 \\
$2-3$ & 33.3 & 30.4 & 28.7 & 29.8 \\
$2-4$ & 0.0 & 27.0 & 23.0 & 25.7 \\
$2-5$ & 0.0 & 29.5 & 27.2 & 21.9 \\
$3-1$ & 0.0 & 27.3 & 29.6 & 22.6 \\
$3-2$ & 34.3 & 26.7 & 25.2 & 24.6 \\
$3-3$ & 0.0 & 33.2 & 28.4 & 24.4 \\
$3-4$ & 0.0 & 36.0 & 30.2 & 28.3 \\
\hline
\end{tabular}

${ }^{\mathrm{a}}$ MPI $=$ months post inoculation and 0.0 indicates undetermined quantitative cycle value (i.e., negative results).

${ }^{\text {b }}$ S. buxifolia plant number. were available on receptor plants for psyllid feeding, 10 psyllids from source plants were collected and transferred onto one receptor plant for at least 14 days of inoculation access period (IAP; 4). Another 10 psyllids were assayed individually by HLBasrp qPCR (Table 1) to obtain ' $\mathrm{Ca}$. L. asiaticus'-positive percentage data for each transmission experiment. Healthy receptor plants were mock inoculated with healthy psyllids as negative controls, while healthy sweet orange plants inoculated with psyllids from infected source plants served as positive controls. Plants were allowed to grow in the psyllid room for the first 2 months PI, after which inoculated plants were cleaned (psyllids were collected and tested individually) and moved to the third greenhouse for long-term monitoring and observation. Leaves from all of the receptor plants were collected for qPCR test at 2 months PI for the first time, then tested monthly. Receptor plants testing negative were monitored for up to 1 year.

For each psyllid transmission pathway, using psyllids collected from the same source plants, three groups of receptor plants (2 to 12 plants in each group, depending on the plant and psyllid availability) were used to set up three separate transmission experiments, which served as three repeats of each pathway to validate the results. Starting from spring 2010, for transmission pathway 1, $12 \mathrm{~S}$. buxifolia plants were inoculated over a period of 9 months (Table 2 ); for pathway 2, 28 Valencia sweet orange (C. sinensis Valencia) plants were inoculated over a 5-month period (Table 3); and for pathway 3,16 S. buxifolia seedlings were used over a 10-month period (Table 4). Positive and negative controls were set up for each of the three transmission experiment repeats, respectively.

DNA extraction. For plant material, DNA samples were extracted from newly matured leaves using the DNeasy Plant Mini Kit (Qiagen) according to the manufacturer's protocol. Briefly, leaf midribs or petioles from three to five randomly selected leaves were finely chopped with sterile razor blades. Chopped tissue (100 $\mathrm{mg}$ ) was weighed out and put into a 2-ml microcentrifuge tube and pulverized using TissueLyser II (Qiagen) with liquid nitrogen, after which the tissue was ready for DNA extraction with the Plant Kit (Qiagen). For psyllids, the DNeasy Blood and Tissue Kit (Qiagen) was used. Briefly, a single psyllid was placed into a 1.5 -ml micro-

Table 3. Detection of 'Candidatus Liberibacter asiaticus' in Valencia sweet orange inoculated by psyllids from infected Severinia buxifolia

\begin{tabular}{|c|c|c|c|c|c|c|c|c|c|c|}
\hline \multirow[b]{2}{*}{ Plant } & \multicolumn{10}{|c|}{ Quantitative threshold cycle for assays 1-10 (months post inoculation) ${ }^{\mathrm{a}}$} \\
\hline & $1(2)$ & $2(5)$ & $3(8)$ & $4(10)$ & $5(12)$ & $6(14)$ & $7(16)$ & $8(18)$ & $9(20)$ & $10(24)$ \\
\hline $1-1$ & 0.0 & 24.7 & 25.8 & 24.1 & 22.5 & 21.6 & 23.4 & 21.0 & 20.6 & 18.4 \\
\hline $1-2$ & 0.0 & 0.0 & 0.0 & 0.0 & 0.0 & $\ldots$ & $\ldots$ & $\ldots$ & $\ldots$ & $\ldots$ \\
\hline $1-3$ & 0.0 & 0.0 & 0.0 & 0.0 & 0.0 & $\ldots$ & $\ldots$ & $\ldots$ & $\ldots$ & $\ldots$ \\
\hline $1-4$ & 0.0 & 27.3 & 23.9 & 22.4 & 20.9 & 21.2 & 23.1 & 21.9 & 20.6 & 19.3 \\
\hline $1-5$ & 35.2 & 27.7 & 24.5 & 22.9 & 21.4 & 23.4 & 23.6 & 20.9 & 19.4 & 20.2 \\
\hline $1-6$ & 0.0 & 0.0 & 0.0 & 0.0 & 0.0 & $\ldots$ & $\ldots$ & $\ldots$ & $\ldots$ & $\ldots$ \\
\hline $1-7$ & 0.0 & 26.8 & 24.0 & 22.4 & 21.0 & 22.2 & 23.6 & 20.8 & 20.2 & 18.3 \\
\hline $1-8$ & 0.0 & 0.0 & 0.0 & 0.0 & 0.0 & $\ldots$ & $\ldots$ & $\ldots$ & $\ldots$ & $\ldots$ \\
\hline $1-9$ & 0.0 & 0.0 & 0.0 & 0.0 & 0.0 & $\ldots$ & $\ldots$ & $\ldots$ & $\ldots$ & $\ldots$ \\
\hline $1-10$ & 37.3 & 0.0 & 0.0 & 0.0 & 0.0 & $\ldots$ & $\ldots$ & $\ldots$ & $\ldots$ & $\ldots$ \\
\hline $2-1$ & 0.0 & 0.0 & 0.0 & 0.0 & 0.0 & $\ldots$ & $\ldots$ & $\ldots$ & $\ldots$ & $\ldots$ \\
\hline $2-2$ & 0.0 & 35.6 & 26.3 & 24.6 & 23.0 & 21.5 & 22.2 & 20.0 & 19.9 & 20.8 \\
\hline $2-3$ & 0.0 & 0.0 & 25.9 & 24.2 & 22.6 & 22.3 & 23.3 & 20.4 & 21.4 & 19.5 \\
\hline $2-4$ & 0.0 & 0.0 & 0.0 & 0.0 & 0.0 & $\ldots$ & $\ldots$ & $\ldots$ & $\ldots$ & $\ldots$ \\
\hline $2-5$ & 0.0 & 0.0 & 0.0 & 0.0 & 0.0 & $\ldots$ & $\ldots$ & $\ldots$ & $\ldots$ & $\ldots$ \\
\hline $2-6$ & 26.6 & 25.3 & 24.4 & 22.8 & 21.3 & 22.7 & 21.6 & 19.1 & 19.0 & 19.1 \\
\hline $3-1$ & 0.0 & 0.0 & 0.0 & 0.0 & 0.0 & & & $\ldots$ & $\ldots$ & $\ldots$ \\
\hline $3-2$ & 36.0 & 29.4 & 31.1 & 29.1 & 27.2 & 22.6 & 26.5 & 19.4 & 20.1 & 19.0 \\
\hline $3-3$ & 0.0 & 0.0 & 0.0 & 0.0 & 0.0 & $\ldots$ & $\ldots$ & $\ldots$ & $\ldots$ & $\ldots$ \\
\hline $3-4$ & 0.0 & 0.0 & 0.0 & 0.0 & 0.0 & $\ldots$ & $\ldots$ & $\ldots$ & $\ldots$ & $\ldots$ \\
\hline $3-5$ & 0.0 & 0.0 & 0.0 & 0.0 & 0.0 & & & $\ldots$ & & . \\
\hline $3-6$ & 31.5 & 30.9 & 24.0 & 22.4 & 20.9 & 20.6 & 24.8 & 21.0 & 20.7 & 21.2 \\
\hline $3-7$ & 31.2 & 28.9 & 23.1 & 21.5 & 20.1 & 24.6 & 25.0 & 20 & 20.1 & 18.7 \\
\hline $3-8$ & 0.0 & 0.0 & 0.0 & 0.0 & 0.0 & $\ldots$ & $\ldots$ & $\ldots$ & $\ldots$ & $\ldots$ \\
\hline 3-9 & 0.0 & 0.0 & 0.0 & 0.0 & 0.0 & $\ldots$ & $\ldots$ & $\ldots$ & $\ldots$ & $\ldots$ \\
\hline $3-10$ & 25.9 & 25.1 & 22.9 & 21.4 & 20.0 & 24.3 & 24.3 & 20.8 & 19.1 & 20.7 \\
\hline $3-11$ & 27.0 & 25.9 & 28.5 & 26.7 & 24.9 & 21.6 & 24.8 & 20.9 & 19.8 & 20.7 \\
\hline $3-12$ & 28.2 & 31.3 & 24.3 & 22.7 & 21.2 & 22.1 & 24.0 & 20.7 & 21.1 & 19.6 \\
\hline
\end{tabular}

${ }^{a}$ Undetermined quantitative cycle value indicated by 0.0 (i.e., negative results) and ... indicates plant died or was discarded. 
centrifuge tube with $180 \mu \mathrm{l}$ of ATL buffer (tissue lysis buffer from the DNeasy Blood and Tissue Kit) and ground with a pestle; then, the total DNA was extracted following the manufacturer's protocol. The yield and purity of the DNA samples was estimated with a NanoDrop Spectrophotometer ND-1000, and all DNA samples were stored at $-20^{\circ} \mathrm{C}$.

Detection assays. The HLBasrp qPCR system was used as the primary method for ' $C a$. L. asiaticus' detection (20), while several other qPCR (i.e., CQUfrp, rpoBfrp, Lasfrp, Laffrp, and Lamfrp) and conventional PCR (i.e., ARfr) assays were also used to further confirm the identity of the transmitted agent $(1,23,34$; Table 1$)$. Internal controls (ICs) were included to assess the quality of the DNA extracts and the reaction mixtures. For plant samples, the IC was a plant cytochrome oxidase-based primer/probe set (20) and, for psyllid samples, a psyllid glycoprotein gene was used (23). All primers and probes were synthesized by Integrated DNA Technologies Inc.

All qPCRs were performed on an Applied Biosystems 7500 Fast Real-Time PCR System (Life Technologies) and all of the qPCRs used the same protocol, as follows: 2 min of incubation at $50^{\circ} \mathrm{C}$ followed by $10 \mathrm{~min}$ of incubation at $95^{\circ} \mathrm{C}$, then 40 cycles of $15 \mathrm{~s}$ at $95^{\circ} \mathrm{C}$ and $1 \mathrm{~min}$ at $60^{\circ} \mathrm{C}$. Fluorescent signals were collected after 1 min at $60^{\circ} \mathrm{C}$ during each cycle. A $20-\mu$ l qPCR mixture contained $10 \mu \mathrm{l}$ of $2 \times$ ABI TaqMan Universal PCR Master Mix (Life Technologies), $2 \mu \mathrm{l}$ of DNA template, appropriate amounts of primer or probe stock (to reach the optimized final concentrations as listed in Table 1), and nuclease-free water (Qiagen). All reactions were performed in triplicate and each run contained one negative, one positive, and one healthy control. qPCR data were analyzed with the Applied Biosystems software (version 1.4.0.).

In order to confirm the results from qPCRs, qPCRs were run again using conventional PCR (without probes, while the PCR protocol remained the same) to check for actual bands under the UV light (Table 1). For conventional PCR, all reactions were run on an S1000 Thermal Cycler (Bio-Rad). A 50- $\mu$ l PCR mixture contained $25 \mu \mathrm{l}$ of $2 \times$ GoTaq Green Master Mix (Promega Corp.), $6 \mu \mathrm{l}$ of DNA template, and appropriate amounts of primer stock and nuclease-free water (Qiagen). Amplified PCR products were run using $1 \%$ agarose gel stained with GelRed (Biotium) and visualized with AlphaImager EP (AlphaInnotech). After visualization of bands of the expected size, all PCR products were sent for sequencing at the Interdisciplinary Center for Biotechnology Research, University of Florida, Gainesville. All sequence data were blasted online at National Center for Biotechnology Information website (http://blast.ncbi.nlm.nih.gov/Blast.cgi).

Monitoring of the live ' $\mathrm{Ca}$. L. asiaticus' population change. In order to monitor the dynamic change of the live ' $\mathrm{Ca}$. L. asiaticus' population inside host plants, some of the successfully inocu- lated plants were tested monthly by PMA-qPCR (14). These plants included three Valencia sweet orange $(C$. sinensis Valencia) and three $S$. buxifolia plants inoculated by either grafting or psyllid. The monitoring lasted 20 months, from August 2010 to April 2012. PMA pretreatment on plant samples was conducted following the protocol published by $\mathrm{Hu}$ et al. (14). Briefly, about $120 \mathrm{mg}$ of finely chopped midrib or petiole tissue was pulverized with the TissueLyser II (Qiagen) with liquid nitrogen to make a homogenized tissue pool, and two portions of the 50-mg tissue powder from this pool were weighed out and received differential treatments. One portion of the $50 \mathrm{mg}$ of tissue was mixed with $1 \mathrm{ml}$ of PMA solution (final concentration of $25 \mu \mathrm{g} / \mathrm{ml}$ ) and incubated in the dark for $5 \mathrm{~min}$, after which it received $2 \mathrm{~min}$ of light exposure from a halogen bulb $(650 \mathrm{~W})$ at a distance of $20 \mathrm{~cm}$ from the light source. The other portion of the 50-mg tissue sample received the same physical treatments, only without PMA added. After $5 \mathrm{~min}$ of centrifugation at $13,200 \mathrm{rpm}(16,100 \times g), 800 \mu \mathrm{l}$ of the supernatant was discarded from each tube and the remaining pellets were used for DNA extraction with DNeasy Plant Mini Kit (Qiagen). The HLBasrp qPCR assay was used for ' $\mathrm{Ca}$. L. asiaticus' detection after the PMA treatment (20). Quantitative threshold cycle $(\mathrm{Cq})$ values from the PMA-qPCR assay were converted into bacterial population number with the standard curve developed by $\mathrm{Hu}$ et al. (14). The bacterial population detected from the PMAtreated sample represented the GLB while the one detected from the no-PMA-added sample represented the TGP.

Statistical analysis. To compare the ' $\mathrm{Ca}$. L. asiaticus' population in psyllids which were raised on ' $C a$. L. asiaticus'-positive Rough lemon and $S$. buxifolia plants, an $F$ test from two-way analysis of variance (ANOVA) as a post hoc test was performed on logconverted bacterial population data of 10 individual psyllids from each plant species. To compare the bacterial population (GLB or TGP) between the 3 months of December, January, and February and the other months, the bacterial populations in each of the three plant replicates were averaged within each time period (the 3 months of December, January, and February versus the other months), and were analyzed with an $F$ test from ANOVA using the General Linear Model procedure. All the statistical analysis was done with SAS 9.3 TS Level 1M0 at the significant level of $P<$ 0.05 .

\section{Results}

' $\mathrm{Ca}$. L. asiaticus'-transmission experiments. For graft-inoculation experiments, all of the grafted $S$. buxifolia and Valencia sweet orange plants became ' $\mathrm{Ca}$. L. asiaticus' positive in the first qPCR test at 4 months PI. Graft-inoculated Severinia plants hosted a population of ' $\mathrm{Ca}$. L. asiaticus', comparable with the bacterial population detected in Valencia sweet orange, for over 33 months

Table 4. Detection of 'Candidatus Liberibacter asiaticus' in Severinia buxifolia inoculated by psyllids from infected S. buxifolia

\begin{tabular}{|c|c|c|c|c|c|c|c|c|c|c|c|c|c|c|c|c|}
\hline \multirow[b]{2}{*}{ Plant } & \multicolumn{16}{|c|}{ Quantitative threshold cycle for assays 1-16 (months post inoculation) $^{\mathrm{a}}$} \\
\hline & $1(2)$ & $2(5)$ & $3(8)$ & $4(9)$ & $5(10)$ & $6(11)$ & $7(12)$ & $8(13)$ & $9(14)$ & $10(15)$ & $11(16)$ & $12(17)$ & $13(18)$ & $14(19)$ & $15(20)$ & $16(24)$ \\
\hline $1-1$ & 0.0 & 33.9 & 28.3 & 27.3 & 22.8 & 23.6 & 23.9 & 23.8 & 24.1 & 23.5 & 22.5 & 23.3 & 23.1 & 22.9 & 24.3 & 22.1 \\
\hline $1-2$ & 35.7 & 30.3 & 26.7 & 24.1 & 26 & 26.1 & 26.1 & 23.8 & 22.5 & 25.4 & 25.5 & 22 & 24 & 23.1 & 23 & 26.2 \\
\hline $2-1$ & 0.0 & 0.0 & 0.0 & 0.0 & 0.0 & 0.0 & 0.0 & $\ldots$ & $\ldots$ & $\ldots$ & $\ldots$ & $\ldots$ & $\ldots$ & $\ldots$ & $\ldots$ & $\ldots$ \\
\hline $2-2$ & 0.0 & 0.0 & 0.0 & 0.0 & 0.0 & 0.0 & 0.0 & $\ldots$ & $\ldots$ & $\ldots$ & $\ldots$ & $\ldots$ & $\ldots$ & $\ldots$ & $\ldots$ & $\ldots$ \\
\hline $2-3$ & 0.0 & 26 & 27.9 & 27.4 & 23.2 & 27.7 & 25.3 & 26.8 & 25.3 & 23.8 & 24 & 22.4 & 26.8 & 24.3 & 24.6 & 23.9 \\
\hline $2-4$ & 34.5 & 26.8 & 22.6 & 22.6 & 25.6 & 25.4 & 27.9 & 23.3 & 25.3 & 21.5 & 24.1 & 22.5 & 24.8 & 25.1 & 23.8 & 24.9 \\
\hline $2-5$ & 0.0 & 25.8 & 24 & 27.4 & 22.1 & 24.5 & 21.3 & 23.7 & 23 & 21.2 & 22.6 & 20 & 25.5 & 27.1 & 26 & 24.8 \\
\hline $2-6$ & 0.0 & 25.8 & 25.8 & 27.8 & 25.5 & 28.7 & 28.1 & 23.8 & 23.4 & 21.8 & 23.7 & 23.4 & 23.9 & 28.3 & 23.9 & 26.6 \\
\hline $2-7$ & 0.0 & 0.0 & 0.0 & 0.0 & 0.0 & 0.0 & 0.0 & & & & & & & 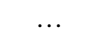 & & \\
\hline $2-8$ & 0.0 & 23.9 & 23.3 & 24.2 & 21.5 & 22 & 22.3 & 25.3 & 24.4 & 22.6 & 25.5 & 22.5 & 22.2 & 26.9 & 28.4 & 24 \\
\hline $2-9$ & 0.0 & 0.0 & 24 & 36.3 & 23.5 & 27.4 & 26.9 & 27.4 & 24.3 & 22.2 & 25.2 & 20.4 & 24.3 & 28.2 & 25.2 & 24.9 \\
\hline $3-1$ & 0.0 & 38.3 & 35.7 & 30.8 & 25.3 & 22.7 & 23.8 & $\mathrm{NP}$ & NP & NP & NP & NP & NP & NP & NP & NP \\
\hline $3-2$ & 0.0 & 0.0 & 0.0 & 0.0 & 0.0 & 0.0 & 0.0 & & $\ldots$ & $\ldots$ & $\ldots$ & $\ldots$ & $\ldots$ & $\ldots$ & $\cdots$ & \\
\hline $3-3$ & 0.0 & 38.9 & 36.3 & 28.9 & 27.3 & 23.8 & 25.1 & NP & NP & NP & NP & NP & NP & NP & NP & NP \\
\hline $3-4$ & 37.8 & 29.2 & 27.2 & 24.3 & 20.4 & 22.1 & 21.6 & NP & NP & NP & NP & NP & NP & NP & NP & NP \\
\hline $3-5$ & 0.0 & 37.6 & 35.1 & 30.3 & 24.5 & 23.0 & 21.5 & NP & NP & NP & NP & NP & NP & NP & NP & NP \\
\hline
\end{tabular}

${ }^{a}$ Undetermined quantitative cycle value indicated by 0.0 (i.e., negative results), ... indicates plant died or was discarded, and NP indicates no quantitative polymerase chain reaction data point. 
(from July 2009 to April 2012). For psyllid-transmission experiments, ' $C a$. L. asiaticus' could be transmitted successfully in all three transmission pathways at different rates (Tables 2-4). Regarding symptoms, citrus plants in graft and psyllid-transmission experiments (including Rough lemon source plants and Valencia sweet orange receptor plants) all showed typical HLB symptoms such as blotchy mottle leaves and various growth issues (i.e., stunting, dieback) after ' $C a$. L. asiaticus' infection was confirmed. For Severinia plants, stunted growth was observed in all of the ' $\mathrm{Ca}$. L. asiaticus'-infected plants (Fig. 1B), while leaf symptoms such as chlorosis (Fig. 1A), small leaves, and corky veins could be observed in both ' $\mathrm{Ca}$. L. asiaticus'-positive and -negative Severinia plants. All the control plants in graft- and psyllid-transmission experiments tested as expected (i.e., positive control plants became qPCR ' $C a$. L. asiaticus' positive and showed certain symptoms while mock-inoculated negative control plants remained ' $C a$. L. asiaticus' negative and produced healthy growth).

In psyllid-transmission experiments, psyllids fed on Severinia plants without any obvious adaptive phase, and colonies established on Severinia plants as rapidly as on sweet orange or $M$. paniculata plants (as observed in the healthy cage). Various signs of psyllid activities, such as honeydew, eggs and nymphs, could be easily observed on Severinia plants. After the 3-week AAP, the majority of the psyllids ( 80 to $100 \%$ ) raised on ' $\mathrm{Ca}$. L. asiaticus'positive Severinia plants acquired a substantial amount of ' $\mathrm{Ca}$. L. asiaticus' bacterium $\left(1.6 \times 10^{6}\right.$ to $6.1 \times 10^{7}$ ' $\mathrm{Ca}$. L. asiaticus'

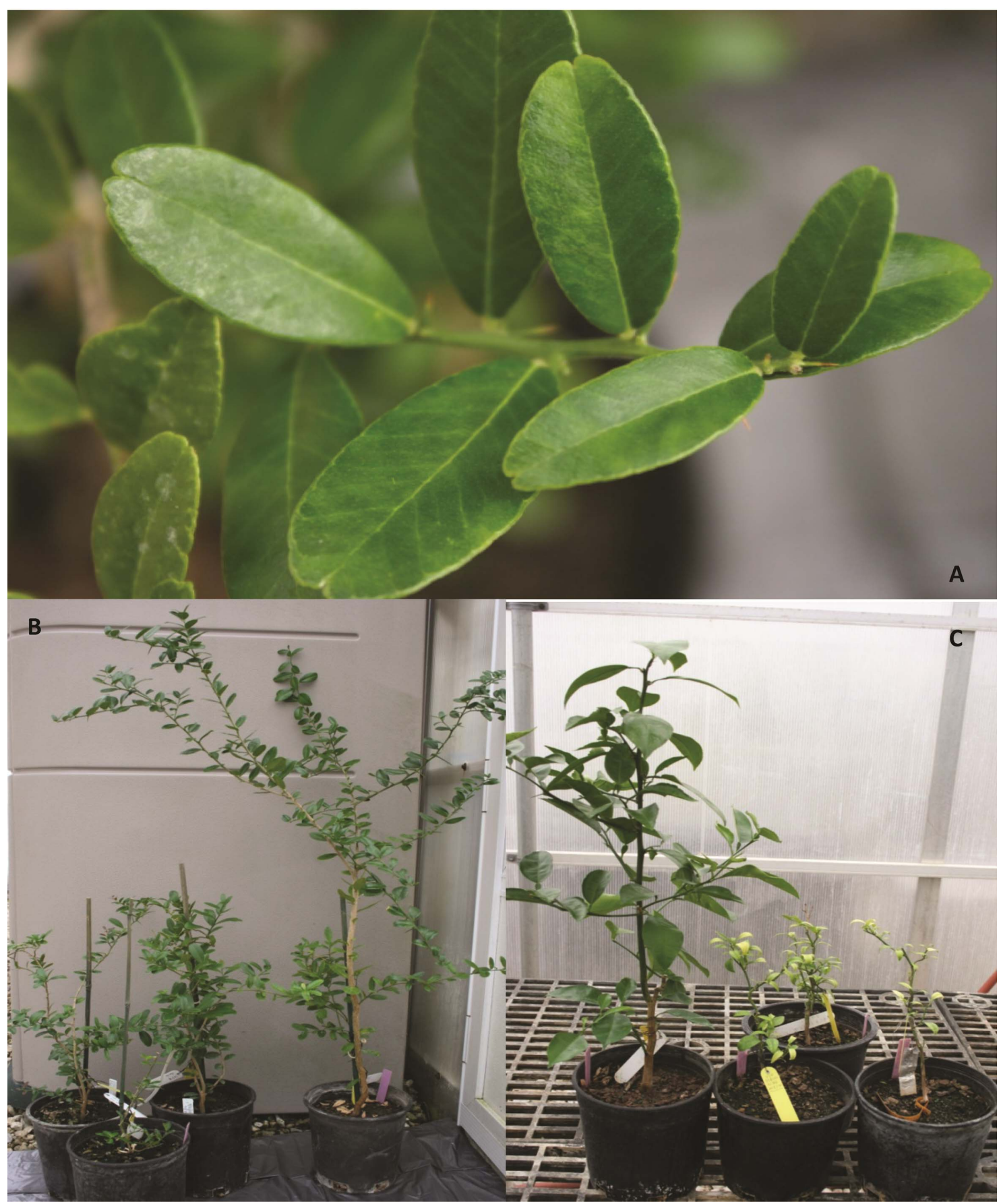

Fig. 1. Symptoms observed in huanglongbing transmission experiments of Severinia buxifolia. A, Blotchy mottle on S. buxifolia leaves. After infection with 'Candidatus Liberibacter asiaticus', S. buxifolia plants showed some chlorotic leaves but a similar symptom was also observed in some 'Ca. L. asiaticus'-negative S. buxifolia plants (i.e., inoculated by psyllids in this study but not successfully infected by ' $\mathrm{Ca}$. L. asiaticus'); therefore, it was considered to be an undetermined symptom. The only symptom that always agreed with quantitative polymerase chain reaction results was stunting of plants. B, Stunted S. buxifolia and C, stunted Valencia sweet orange; tall plants were negative controls. 
cells/psyllid), which was not significantly different from the bacterial population found in psyllids raised on HLB-affected Rough lemon plants $\left(5.1 \times 10^{6}\right.$ to $1.3 \times 10^{8}$ ' $\mathrm{Ca}$. L . asiaticus' cells/psyllid; $F$ test; $F=1.64$; df 1,$18 ; P>F<0.2160)$. In psyllid-transmission pathway 1 (citrus to Severinia), all of the receptor Severinia plants were infected by ' $\mathrm{Ca}$. L. asiaticus' ( $100 \%$ transmission rate) and some of the Severinia plants were ' $\mathrm{Ca}$. L. asiaticus' positive as early as 2-month PI. All of the positive plants still hosted a substantial population of ' $\mathrm{Ca}$. L. asiaticus' at 12 months PI (Cq 25 to 29; Table 2). In pathway 2 (Severinia to citrus), the psyllid vector could obtain a substantial amount of ' $C a$. L. asiaticus' bacteria from the Severinia source plants $\left(1.1 \times 10^{6}\right.$ to $7.1 \times 10^{7}{ }^{\prime} \mathrm{Ca}$. L. asiaticus' cells/psyllid) but less than half of the Valencia sweet orange plants were infected by ' $\mathrm{Ca}$. L. asiaticus' (13 of 28 total inoculated plants, $46.4 \%$ transmission rate). ' $\mathrm{Ca}$. L. asiaticus' in positive citrus plants quickly reached a high population $(\mathrm{Cq}<30)$ and the bacterium persisted and multiplied for more than 24 months (Cq values of 19 to 31 since 8 months PI) (Table 3$)$. In the psyllid transmission pathway 3 (Severinia to Severinia), the total transmission rate of three trials was $75 \%$ (12 positive out of 16 total inoculated plants). As in transmission pathway 1 , most of the positive Severinia receptor plants became positive at the second qPCR test 5 months PI, and the ' $\mathrm{Ca}$. L. asiaticus' bacterium quickly reached a high population $(\mathrm{Cq}$ values of 22 to 28 since 10 months PI) in Severinia and lasted for more than 24 months (Table 4).

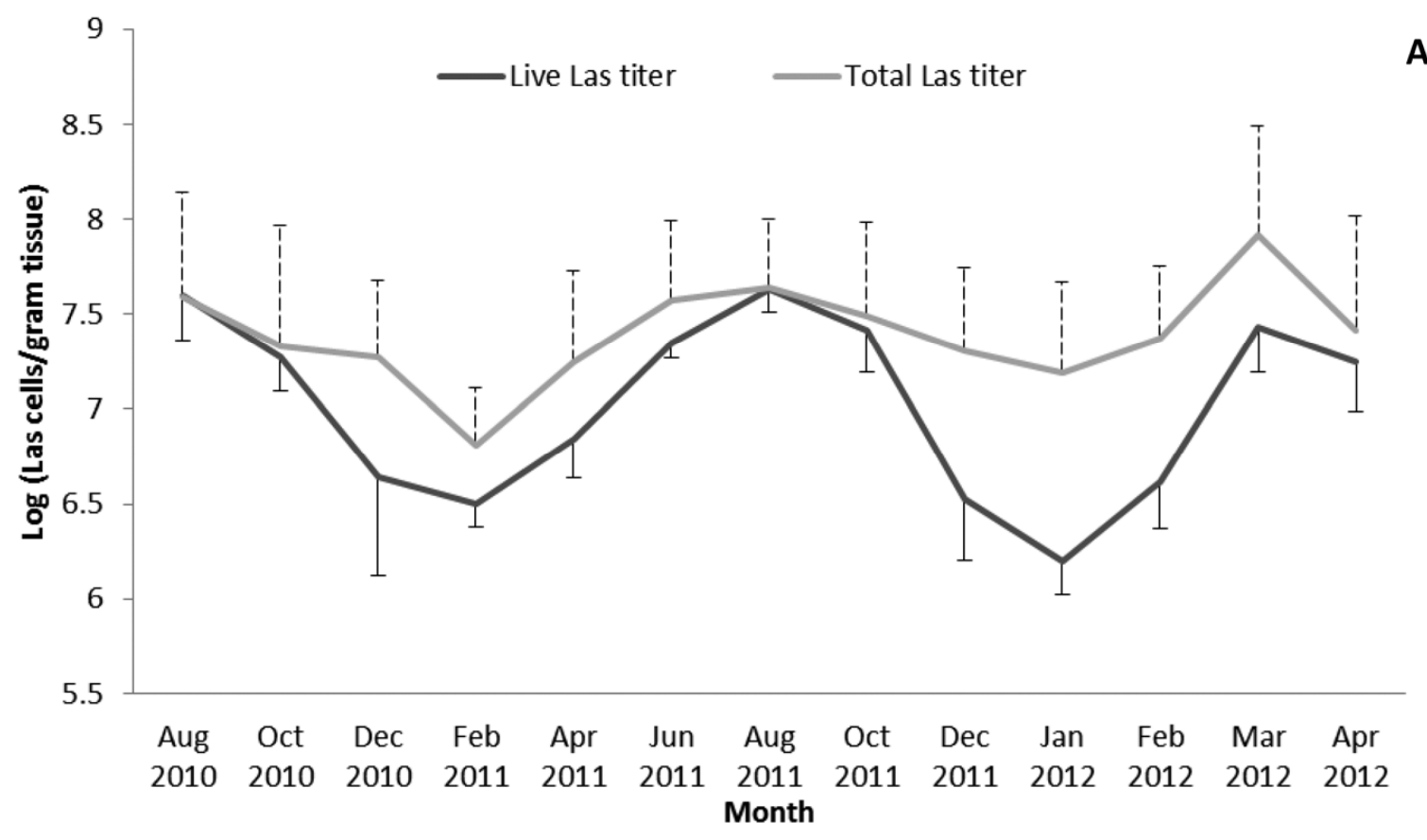

A

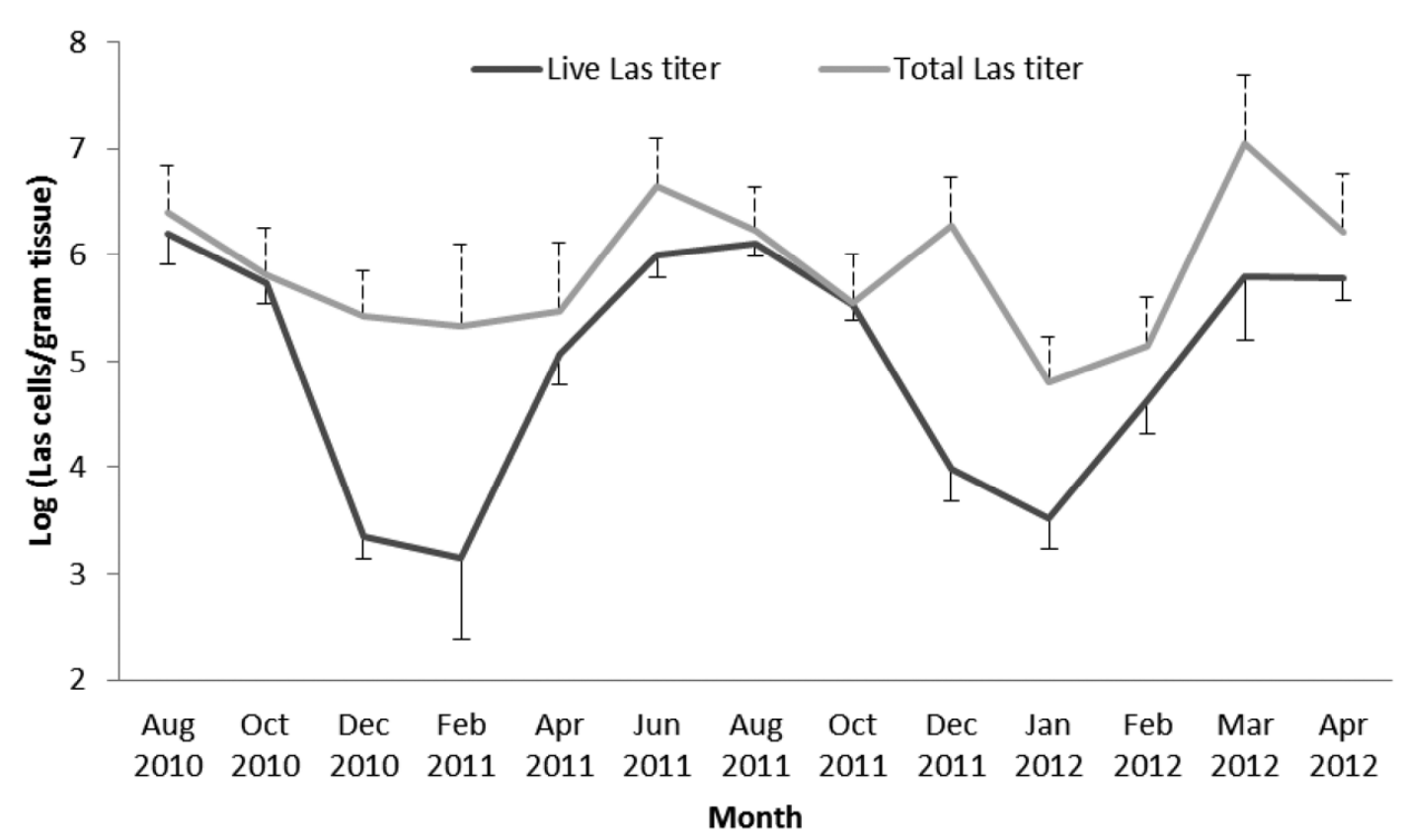

Fig. 2. Dynamics of live and total genomes of 'Candidatus Liberibacter asiaticus' (Las) in graft-inoculated Valencia sweet orange (Citrus sinensis 'Valencia') and Severinia buxifolia plants over a 20 -month period. After successful inoculation by grafting, 'Ca. L. asiaticus'-positive Valencia sweet orange and S. buxifolia plants were monitored on a monthly basis by propidium monoazide in conjunction with real-time quantitative polymerase chain reaction. Monitoring started in August 2010 and lasted for 20 months, through April 2012. Error bars represent standard deviations within three plants. 'Ca. L. asiaticus' dynamics in A, Valencia sweet orange (C. sinensis 'Valencia) and B, S. buxifolia. 
'Ca. L. asiaticus' identity confirmation. 'Ca. L. asiaticus' identity was confirmed with multiple assays. Five additional qPCR assays, which targeted different regions of the bacterial genome, were used to retest the positive plant samples by HLBasrp assay (20; Table 1). Positive qPCR results were obtained with CQUfrp, rpoBfrp, and Lasfrp assays while negative results were obtained with Lamfrp and Laffrp systems. Second, all qPCR primer sets plus one conventional PCR primer set, ARfr, were run on the regular thermocycler and actual bands with expected amplicon sizes were visualized in the gel. The PCR products were purified and sent for DNA sequencing. The 2.588-bp product of the ARfr assay was first cloned and then sent for sequencing due to the large size of the PCR product. Sequence data were compared and confirmed to be a ' $C a$. L. asiaticus' sequence with more than $99 \%$ similarity.

Dynamic change of live ' $\mathrm{Ca}$. $\mathrm{L}$. asiaticus' population. A significantly lower GLB was found in the months of December, January, and February in S. buxifolia and Valencia sweet orange, both graft- and psyllid-inoculated plants. However, the same type of data was not seen with TGP assays.

Specifically, the GLB in graft-inoculated Valencia sweet orange maintained a high level of $10^{7}$ to $10^{8}$ ' $\mathrm{Ca}$. L. asiaticus' cells/g of tissue in most of the months except for December, January, and February, where it dropped to a significantly lower level of about $10^{6}$ to $10^{7}$ ' $\mathrm{Ca}$. L. asiaticus' cells/g of tissue ( $F$ test; $F=293.66$; df 1,$4 ; P>F<0.0001$; Fig. 2A). The TGP dynamics in graft-inoculated Valencia followed a similar pattern, and the TGP in December, January, and February was significantly lower than the rest of the year ( $F$ test; $F=42$; df 1,$4 ; P>F<0.0029$; Fig. 2A). In graftinoculated $S$. buxifolia plants, the GLB dynamics also followed the same pattern as that in Valencia sweet orange, except fluctuating on a lower population level (from $10^{3}$ to $10^{6}$ ' $\mathrm{Ca}$. L. asiaticus' cells/g of tissue compared with $10^{6}$ to $10^{8}$ of GLB in graft-inoculated citrus), and GLB maintained a significantly higher level in most of the months than in the 3-month period of December, January, and February ( $F$ test; $F=15533.9 ;$ df 1,$4 ; P>F<0.0001$; Fig. 2B); however, the TGP fluctuated more randomly and no sig- nificant difference was observed in the 3 months of December, January, and February compared with the rest of the year ( $F$ test; $F$ $=1541.98$; df 1,$4 ; P>F<0.0682$; Fig. 2B). For psyllid-transmitted $S$. buxifolia, after the initial 8 months, the GLB followed the previous pattern; that is, significantly lower level of GLB populations $\left(10^{5}\right.$ to $10^{6}$ ' $\mathrm{Ca}$. L. asiaticus' cells/g of tissue) during the 3 months of December 2011 to February 2012 compared with those in the other months $\left(10^{6}\right.$ to $10^{7}$ ' $\mathrm{Ca}$. L. asiaticus' cells/g of tissue; $F$ test; $F=328.56$; df 1, 4; $P>F<0.0001$; Fig. 3). The dynamics of the TGP showed a random fluctuation, and no statistically significant difference was observed in the 3 months of December, January, and February compared with the rest of the year ( $F$ test; $F=$ 5.1; df 1, 4; $P>F<0.0869$; Fig. 3).

\section{Discussion}

S. buxifolia as a good alternative host for both ' $\mathrm{Ca}$. L. asiaticus' and the psyllid vector. In this study, it has been demonstrated with repeated transmission experiments that ' $\mathrm{Ca}$. L. asiaticus' could be transmitted by psyllid in all of the transmission pathways involving $S$. buxifolia (i.e., from citrus to $S$. buxifolia, from $S$. buxifolia back to citrus, and from $S$. buxifolia to $S$. buxifolia), and by grafting from citrus to $S$. buxifolia. The psyllid vector easily infested S. buxifolia without any obvious adaptive phase, and psyllid activities such as feeding and reproducing were just as common as those seen on citrus and orange jasmine ( $M$. paniculata). In addition, psyllids raised on positive $S$. buxifolia plants could easily acquire ' $\mathrm{Ca}$. L. asiaticus' bacterium ( 80 to $100 \%$ of the psyllids tested were ' $\mathrm{Ca}$. L. asiaticus' positive, $1.6 \times 10^{6}$ to $6.1 \times 10^{7}$ ' $\mathrm{Ca}$. L. asiaticus' cells/psyllid). In order to serve as an inoculum reservoir, a plant species should be able to retain the pathogen in an infectious state over an extended period of time (4). Our data showed that ' $\mathrm{Ca}$. L. asiaticus' persisted at a high population level in $S$. buxifolia plants for more than 33 months, and the psyllid acquired the ' $\mathrm{Ca}$. L. asiaticus' bacterium from positive $S$. buxifolia plants from as early as 5 months PI and they acquired the bacterium throughout the monitored period. Therefore, $S$. buxifolia is a

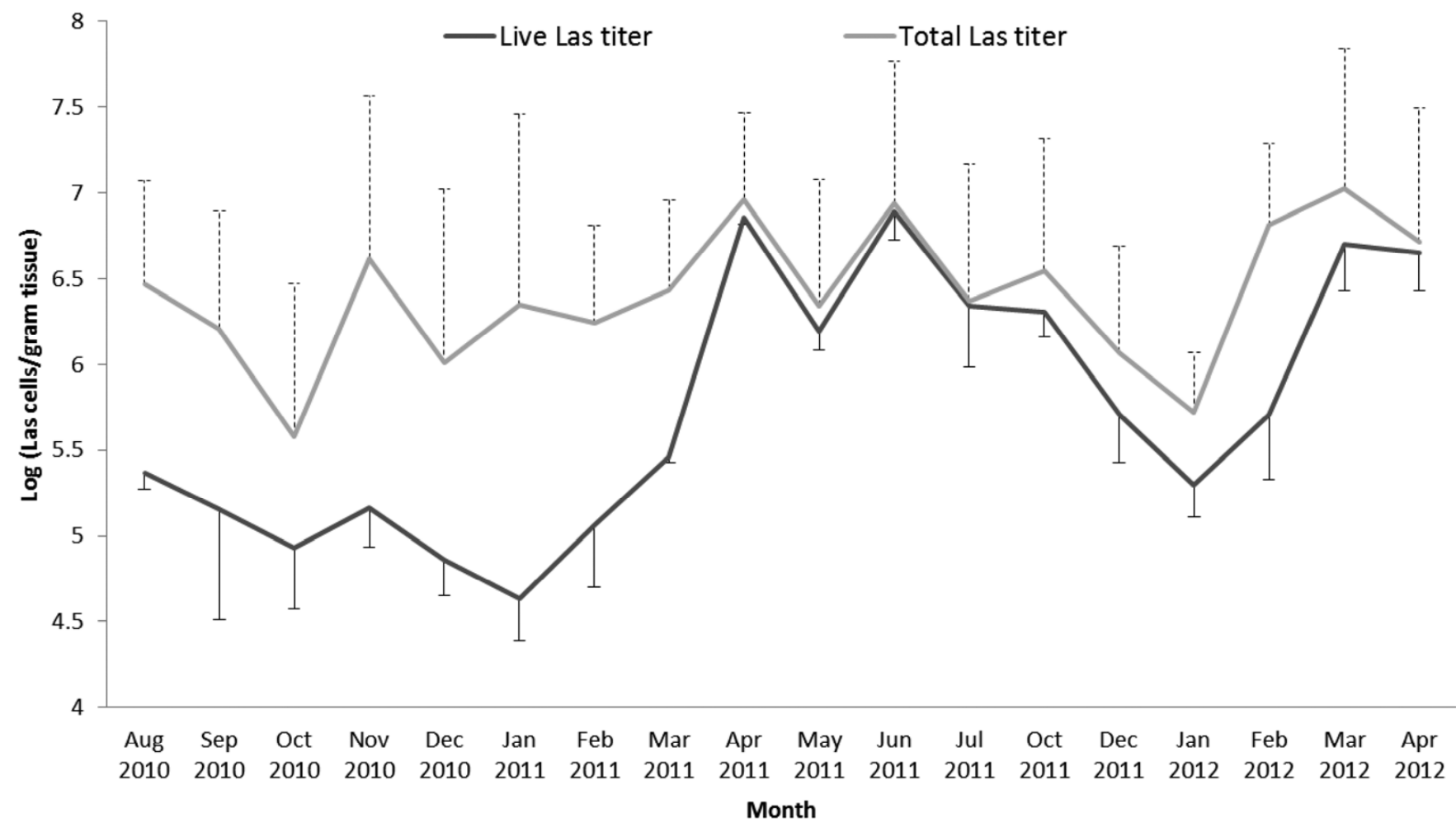

Fig. 3. Dynamics of live and total genome of 'Candidatus Liberibacter asiaticus' (Las) in psyllid-transmitted Severinia buxifolia plants over a 20-month period. After successful inoculation by psyllids, three 'Ca. L. asiaticus'-positive $S$. buxifolia plants were chosen to be monitored monthly by propidium monoazide in conjunction with real-time quantitative polymerase chain reaction. Monitoring started in August 2010 and lasted for 20 months through April 2012. Error bars represent standard deviations within three plants. 
good alternative host and reservoir of both the ' $\mathrm{Ca}$. L. asiaticus' bacterium and the psyllid vector. Compared with another commonly studied alternative host in HLB research $(4,5,12,36)$, orange jasmine (M. paniculata), $S$. buxifolia is probably a greater threat to HLB management. M. paniculata supports high levels of psyllid populations but only supports ' $\mathrm{Ca}$. L . asiaticus' for a short period at a low population level (i.e., ' $\mathrm{Ca}$. L. asiaticus' becomes undetectable by PCR after 5 months; 4). In fact, field surveys in Florida and Brazil showed that ' $\mathrm{Ca}$. L. asiaticus' incidence in ornamental M. paniculata and associated psyllids (D. citri) was low (for example, 1.8 and $1 \%$ for the Murraya plants and psyllids, respectively, in the Florida field survey; 22,32), while naturally ' $\mathrm{Ca}$. L. asiaticus'-infected S. buxifolia plants have already been found in the field (28). As a common ornamental plant in Florida, S. buxifolia is currently not subject to any quarantine measures with regards to HLB management, such as tree-eradication or psyllid control programs, and the threat of this plant to citrus industries may be underestimated.

Regarding the symptoms caused by ' $C a$. L. asiaticus'-infection, Folimonova et al. (10) reported that $S$. buxifolia was highly tolerant to HLB because it showed few or no visual symptoms and plants continued to grow vigorously, like uninoculated control plants. In this study, no leaf symptoms on S. buxifolia were consistent with PCR results (which made them "undetermined" symptoms). However, stunting was observed in all of the ' $\mathrm{Ca}$. L. asiaticus'-positive $S$. buxifolia, which indicated that plant growth was severely inhibited after ' $C a$. L. asiaticus' infection (Fig. 1B). Because ' $C a$. L. asiaticus' could infect $S$. buxifolia for a long period of time ( $>33$ months), and cause distinctive symptoms, it is clear that ' $\mathrm{Ca}$. $\mathrm{L}$. asiaticus' could cause disease in S. buxifolia which is similar to citrus HLB, and diagnosis of this disease in $S$. buxifolia cannot rely on leaf symptoms.

Live ' $\mathrm{Ca}$. L. asiaticus' population dynamics. It is clear that GLB of ' $\mathrm{Ca}$. L. asiaticus' is lower in the 3 months of December, January, and February than the other months of the year (Fig, 2A and $\mathrm{B}$ ), which is confirmed to be statistically significant ( $F$ test, $P<0.0001)$. This pattern applies to both graft-transmitted Valencia sweet orange and S. buxifolia plants; however, the psyllid-transmitted $S$. buxifolia plants in this study seem not follow this pattern. GLB of ' $C a$. L. asiaticus' was at the same level from August 2010 to February 2011 (Fig. 3), and this was also observed in psyllidtransmitted Valencia sweet orange (14). Graft-transmission experiments on both plant species were conducted in July 2009 and the psyllid-transmission experiments were completed in June 2010. In other words, when the plants were tested by PMA-qPCR starting from August 2010, the 'Ca. L. asiaticus' bacterium already had been present in graft-transmitted plants for more than 1 year whereas, in psyllid-transmitted plants, the bacterium had just established infection (i.e., still in latent period of HLB). It usually took 8 to 10 months for ' $\mathrm{Ca}$. L. asiaticus' bacterium to reach and maintain a stable population level after transmission (Table 2-4); therefore, 8 to 10 months may be the latent period of HLB infection with the specific combination of plant material and growth condition in this study. In fact, it was observed that the successfully inoculated plants started showing leaf symptoms at 8 to 10 months PI. From April 2011 to April 2012, the GLB fluctuation in psyllid-transmitted $S$. buxifolia and Valencia sweet orange followed the pattern observed in Figure 2, and the significant difference between the 3 months of December, January, and February and the other months was confirmed by statistical analysis $(F$ test; $F=328.56$; df 1,4 ; $P>F<0.0001)$. Therefore, this pattern of ' $\mathrm{Ca}$. L. asiaticus' GLB dynamics (or the ' $\mathrm{Ca}$. L. asiaticus' growth pattern) (i.e., ' $\mathrm{Ca}$. L. asiaticus' GLB is lower in December through February than the rest of the year) is a general rule which applies to Valencia sweet orange and $S$. buxifolia inoculated by either grafting or psyllid. Compared with $M$. paniculata, in which the ' $C a$. L. asiaticus' bacterium dies out within 5 months, the common ' $\mathrm{Ca}$. L. asiaticus' growth pattern shared by both Valencia sweet orange and $S$. buxifolia may indicate that these two plant hosts provide similar living environments to ' $\mathrm{Ca}$. L. asiaticus' bacterium.
We resorted to a second technique to verify the data from PMAqPCR in this study, especially the data in Figure 3; however, this attempt was unsuccessful for various reasons. Confocal laser-scanning microscopy was deemed inadequate to address a quantitative issue, or even misleading, due to the uneven distribution of the ' $C a$. L. asiaticus' bacterium inside the phloem. Our attempt to observe and quantify the live or dead bacteria with Membrane Entrapment Fluorescent technique (3) and different combinations of PMA, ethidium monoazide, and various SYTO stains also was unsuccessful due to the interference from plant tissue causing background fluorescence. As far as we know, at the time of this study, there was no technique available for live ' $\mathrm{Ca}$. L. asiaticus' population quantification other than the PMA-qPCR method (14). Therefore, we were unable to utilize a second technique to verify these results. However, the extensive quality-control experiments conducted by $\mathrm{Hu}$ et al. (14) to ensure the data quality of PMAqPCR gave us confidence in the results of this study.

A lot of factors could affect ' $\mathrm{Ca}$. L. asiaticus' growth inside plant hosts and, thus, contribute to the GLB tested. These factors include the initial inoculum, plant age, bacteria growth phase, and environmental conditions (such as light, temperature, water, nutrition, and so on). In this greenhouse study with controlled conditions, many factors could be ruled out when analyzing the reason behind the ' $\mathrm{Ca}$. L. asiaticus' growth pattern. For example, temperature, plant age, and bacterial growth phase are not likely the reasons behind the population fluctuation. Consistent with its obligate intracellular lifestyle, ' $\mathrm{Ca}$. L. asiaticus' lacks many metabolic enzymes typically found in free-living bacteria due to its reduce-sized genome and, therefore, has a close connection with its plant hosts nutritionally (8); thus, bacterial growth is affected by plant growth directly. In Florida, most plants, including citrus and S. buxifolia, have a dormant period during winter time when metabolism and growth of plants is slow. Therefore, the ' $\mathrm{Ca}$. L. asiaticus' growth pattern observed here could be the results of the seasonality of plant growth.

The TGP detected by regular qPCR is less informative due to its mixed nature. For example, the two studies on ' $\mathrm{Ca}$. L. asiaticus' population fluctuation in field-grown citrus plants reported different findings; that is, the TGP in September was found to be either lowest (34) or highest (15) in the year-round observation. However, in this study, no general pattern could be found in the three TGP dynamics, and the TGP in September showed no peak or valley value compared with those in the other months (Figs. 2 and 3). In contrast with TGP, GLB detected by PMA-qPCR could produce more useful data and give better insights. Like a growth curve for culturable bacteria, these GLB dynamics (like a ' $\mathrm{Ca}$. L. asiaticus' growth pattern) inside citrus and non-citrus plant hosts has great potential in various HLB research. For instance, in HLB-transmission experiments, either by grafting or psyllids, it is better to avoid winter time; otherwise, the transmission rate will be lower because the bacteria tested in the inoculum source plants are mostly dead.

In conclusion, $S$. buxifolia is a good alternative host for both ' $\mathrm{Ca}$. L. asiaticus' and the psyllid vector of HLB, whose threat to citrus industries requires more attention. The live ' $\mathrm{Ca}$. L. asiaticus' population detected by PMA-qPCR and the GLB dynamics found in both citrus and $S$. buxifolia should provide useful information on HLB management in Florida.

\section{Literature Cited}

1. Ananthakrishnan, G., Choudhary, N., Roy, A., Sengoda, V. G., Postnikova, E., Hartung, J. S., Stone, A. L., Damsteegt, V. D., Schneider, W. L., Munyaneza, J. E., and Brlansky, R. H. 2013. Development of primers and probes for genus and species specific detection of 'Candidatus Liberibacter species' by real-time PCR. Plant Dis. 97:1235-1243.

2. Bove, J. 2006. Huanglongbing: a destructive, newly-emerging, century-old disease of citrus. J. Plant Pathol. 88:7-37.

3. Brlansky, R. H., Lee, R. F., and Civerolo, E. L. 1990. Detection of Xanthomonas campestris pv. citrumelo and $X$. citri from citrus using membrane entrapment immunofluorescence. Plant Dis. 74:863-868.

4. Damsteegt, V., Postnikova, E., Stone, A., Kuhlmann, M., Wilson, C., Sechler, A., Schaad, N., Brlansky, R., and Schneider, W. 2010. Murraya paniculata and related species as potential hosts and inoculum reservoirs of ' $\mathrm{Can}$ - 
didatus Liberibacter asiaticus', causal agent of huanglongbing. Plant Dis. 94:528-533.

5. Deng, C., Chen, C., Zhao, X., Fu, H., Chen, G., Bai, X., Lou, B., and Wu, R. 2010. Nested-PCR detection of the pathogen of citrus huanglongbing on Clausena lansium and Murraya paniculata. Chin. Agric. Sci. Bull. 26:273276.

6. Deng, X., Lou, Z., Feng, Z., Li, H., Chen, J., and Civerolo, E. 2008. First report of 'Candidatus Liberibacter asiaticus' from Atalantiabuxifolia in Guangdong, China. Plant Dis. 92:314.

7. Ding, F., Wang, G., Yi, G., Zhong, Y., Zeng, J., and Zhou, B. 2005. Infection of wampee and lemon by the citrus huanglongbing pathogen ('Candidatus Liberibacter asiaticus') in China. J. Plant Pathol. 87:207-212.

8. Duan, Y., Zhou, L., Hall, D., Li, W., Doddapaneni, H., Lin, H., Liu, L., Vahling, C., Gabriel, D., Williams, K., Dickerman, A., Sun, Y., and Gottwald, T. 2009. Complete genome sequence of citrus huanglongbing bacterium, 'Candidatus Liberibacter asiaticus' obtained through metagenomics. Mol. Plant-Microbe Interact. 22:1011-1020.

9. Folimonova, S., Robertson, C., Garnsey, S., Gowda, S., and Dawson, W. 2009. Examination of the responses of different genotypes of citrus to huanglongbing (citrus greening) under different conditions. Phytopathology 99:1346-1354.

10. French, J. V., Kahlke, C. J., And da Graca, J. V. 2001. First record of the Asian citrus psylla, Diaphorina citri Kuwayama (Homoptera: Psyllidae), in Texas. Subtrop. Plant Sci. 53:14-15.

11. Garnier, M, Eveillard, S. J., Cronje, P. R., Le Roux, H. F., and Bove, J. M. 2000. Genomic characterization of a liberibacter present in an ornamental rutaceous tree, Calodendrumcapense, in the Western Cape province of South Africa. Proposal of 'Candidatus Liberibacter africanus subsp. capensis'. Int. J. Syst. Evol. Microbiol. 50:2119-2125.

12. Halbert, S., and Manjunath, K. 2004. Asian citrus psyllids (Sternorrhyncha: Psyllidae) and greening disease of citrus: a literature review and assessment of risk in Florida. Fla. Entomol. 87:330-353.

13. Halbert, S. E. 2005. The discovery of huanglongbing in Florida. Page 50 in: Proc. 2nd Int. Citrus Canker and Huanglongbing Workshop, Orlando, FL.

14. Hu, H., Davis, M. J., and Brlansky, R. H. 2013. Quantification of the live 'Candidatus Liberibacter asiaticus' populations using real-time PCR and propidium monoazide. Plant Dis. 97:1158-1167.

15. Hu, H., Yin, Y., Zhang, L., Zhao, Y., Xia, Y., Wang, Z., and Qin, J. 2006. Detection of citrus huanglongbing by conventional and two fluorescence quantitative PCR assays. Sci. Agric. Sin. 39:2491-2497.

16. Hung, T., Wu, M., and Su, H. 2000. Identification of alternative hosts of the fastidious bacterium causing citrus greening disease. J. Phytopathol. Phytopathol. Z. 148:321-326.

17. Hung, T., Wu, M., and Su, H. 2001. Identification of the Chinese box orange (Severinia buxifolia) as an alternative host of the bacterium causing citrus huanglongbing. Eur. J. Plant Pathol. 107:183-189.

18. Kobayashi, H., Oethinger, M., Tuohy, M. J., Hall, G. S., and Bauer, T. W. 2009. Improving clinical significance of PCR: use of propidium monoazide to distinguish live from dead Staphylococcus aureus and Staphylococcus epidermidis. J. Orthop. Res. 27:1243-1247.

19. Koizumi, M., Prommintara, M., and Ohtsu, Y. 1996. Wood apple, Limonia acidissima: a new host for the huanglongbing (greening) vector, Diaphorina citri. Pages 271-275 in: Proc. 13th Conf. Int. Organ. Citrus Virol. (IOCV). J. V. da Graça, P. Moreno, and R. K. Yokomi, eds. University of California, Riverside.

20. Li, W., Hartung, J., and Levy L., 2006. Quantitative real-time PCR for detection and identification of "Candidatus Liberibacter" species associated with citrus huanglongbing. J. Microbiol. Methods 66:104-115.
21. Liang, N., Dong, J., Luo, L., and Li, Y. 2011. Detection of live Salmonella in Lettuce by propidium monoazide real-time PCR. J. Food Sci. 76:M234 237.

22. Lopes, S., Frare, G., Camargo, L., Wulff, N., Teixeira, D., Bassanezi, R., Beattie, G., and Ayres, A. 2010. Liberibacters associated with orange jasmine in Brazil: incidence in urban areas and relatedness to citrus liberibacters. Plant Pathol. 59:1044-1053.

23. Manjunath, K., Halbert, S., Ramadugu, C., Webb, S., and Lee, R. 2008. Detection of 'Candidatus Liberibacter asiaticus' in Diaphorina citri and its importance in the management of citrus huanglongbing in Florida. Phytopathology 98:387-396.

24. Nocker, A., Cheung, C. Y., and Camper, A. K. 2006. Comparison of propidium monoazide with ethidium monoazide for differentiation of live vs. dead bacteria by selective removal of DNA from dead cells. J. Microbiol. Methods 67:310-320.

25. Nocker, A., Sossa, K. E., and Camper, A. K. 2007. Molecular monitoring of disinfection efficacy using propidium monoazide in combination with quantitative PCR. J. Microbiol. Methods 70:252-260.

26. Pelz-Stelinski, K., Brlansky, R., Ebert, T., and Rogers, M. 2010. Transmission Parameters for 'Candidatus Liberibacter asiaticus' by Asian citrus psyllid (Hemiptera: Psyllidae). J. Econ. Entomol. 103:1531-1541.

27. Planet, P., Jagouxie, S., Bové, J. M., and Garnier, M. 1995. Detection and characterization of the African citrus greening liberobacter by amplification, cloning and sequencing of the rplKAJL-ropBC operon. Curr. Microbiol. 30:137-141.

28. Ramadugu, C., Manjunath, K., Halbert, S., Brlansky, R., Roose, M., and Lee, R. 2010. Characterization of huanglongbing associated 'Candidatus Liberibacter asiaticus' from citrus relatives. (Abstr.) Phytopathology 100:S107.

29. Tatineni, S., Sagaram, U., Gowda, S., Robertson, C., Dawson, W., Iwanami, T., and Wang, N. 2008. In planta distribution of 'Candidatus Liberibacter asiaticus' as revealed by polymerase chain reaction (PCR) and real-time PCR. Phytopathology 98:592-599.

30. Teixeira, D. A., Eveillard, S., Martins, E. C., Jesus, W. C., Jr., Yamamoto, P. T., Lopes, S. A., Bassanezi, R. B., Ayres, A. J., Saillard, C., and Bové, J. M. 2005. Citrus huanglongbing in São Paulo State, Brazil: PCR detection of the 'Candidatus Liberibacter' species associated with the disease. Mol. Cell. Probes 19:173-179.

31. Teixeira, D. A., Saillard, C., Eveillard, S., Danet, J. L., da Costa, P. I., Ayres, A. J., and Bové, J. M. 2005. 'Candidatus Liberibacter americanus' associated with citrus huanglongbing (greening disease) in São Paulo State, Brazil. Int. J. Syst. Evol. Microbiol. 55:1857-1862.

32. Walter, A. J., Hall, D. G., and Duan, Y. P. 2012. Low incidence of 'Candidatus Liberibacter asiaticus' in Murraya paniculata and associated Di aphorina citri. Plant Dis. 96:827-832.

33. Wang, N., and Trivedi, P. 2013. Citrus huanglongbing: a newly relevant disease presents unprecedented challenges. Phytopathology 103:652-665.

34. Wang, Z., Yin, Y., Hu, H., Yuan, Q., Peng, G., and Xia, Y. 2006. Development and application of molecular-based diagnosis for 'Candidatus Liberibacter asiaticus', the causal pathogen of citrus huanglongbing. Plant Pathol. 55:630-638.

35. Yanez, M. A., Nocker, A., Soria-Soria, E., Murtula, R., Martinez, L., and Catalan, V. 2011. Quantification of live Legionella pneumophila cells using propidium monoazide combined with quantitative PCR. J. Microbiol. Methods 85:124-130.

36. Zhou, L., Gabriel, D., Duan, Y., Halbert, S., and Dixon, W. 2007. First report of dodder transmission of huanglongbing from naturally infected Murraya paniculata to citrus. Plant Dis. 91:227. 